\title{
Hypothesis
}

\section{Conch Blowing Ameliorates Obstructive Sleep Apnea}

\author{
Rajeev Gupta ${ }^{1}$, Shiva Ahuja ${ }^{2}$, Nishant Gupta ${ }^{3}$ \\ ${ }^{\prime}$ Department of Preventive Cardiology and Internal Medicine, Eternal Heart Care Centre and Research Institute, \\ Jaipur; Academic Research Development Unit, Rajasthan University of Health Sciences, Jaipur; ${ }^{2,3}$ Department of \\ Orthodontics and Oral and Maxillofacial Surgery, KDG Medical and Dental Centre, Hospital Road, Jaipur, \\ Rajasthan, India
}

\begin{abstract}
Obstructive sleep apnea is a major health problem in adults and leads to a variety of cardiovascular, respiratory, neurocognitive, and metabolic problems. Continuous positive airway pressure is therapy of choice. All treatments have low adherence rates. Given the pathogenic importance of oropharyngeal muscles we hypothesized that conch blowing could be useful for improving its severity. A 50-year old gentleman presented to us with daytime somnolence and excessive snoring. Physical examination showed body mass index of 32.0 $\mathrm{kg} / \mathrm{m}^{2}$ with normal examination. Polysomnography showed apnea-hypopnea index of 78.0 and oxygen desaturation index of 74.8. He refused positive airways pressure therapy. He was advised conch blowing, 5 times twice daily. At 12 months follow-up his daytime somnolence decreased, body mass index was $30.8 \mathrm{~kg} / \mathrm{m}^{2}$, apnea-hypopnea index was 50.6, and oxygen desaturation index was 43.7. Mechanistic studies and randomized controlled trials are required to demonstrate benefits of conch blowing in obstructive sleep apnea.
\end{abstract}

\section{INTRODUCTION}

Obstructive sleep apnea (OSA) has emerged as an important global health problem. ${ }^{1}$ There is a paucity of published Indian studies on the prevalence and risk factors of obstructive sleep apnoea in adults. The limited published literature does not suggest significant differences in its prevalence and risk factors as compared to western studies. ${ }^{2}$ With the background of increasing urbanization, fast growing economy, and changes in lifestyle, India already is in the midst of obesity epidemic which is the most important risk factor for OSA syndrome. ${ }^{3}$ OSA is a common disorder of repetitive pharyngeal collapse during sleep. Disturbances in gas exchange lead to oxygen desaturation, hypercapnia, and sleep fragmentation, which lead to consequences of OSA: cardiovascular, respiratory, metabolic, and neurocognitive effects. Its features include snoring, witnessed apneas, and daytime sleepiness. Pathogenesis varies; predisposing factors include small upper airway lumen, unstable respiratory control, low arousal threshold, small lung volume, and dysfunctional upper airway dilator muscles. Risk factors include obesity, male sex, age, menopause, fluid retention, adenotonsillar hypertrophy, and smoking. Obstructive sleep apnea also causes sleepiness, road traffic accidents, and systemic hypertension. It has also been linked to myocardial infarction, congestive heart failure, stroke, and diabetes mellitus.'

Pathophysiology: The basic pathophysiology of OSA syndrome involves heightened susceptibility to collapsing forces such as negative intraluminal pressures that are generated during inspiration and positive extraluminal pressures exerted by the surrounding soft tissues. ${ }^{4}$ Multiple factors are involved and include surface forces, small upper airway lumen, low lung volume, respiratory instability, poor upper airways function, and low arousal thresholds. ${ }^{1}$ Muscles within the upper airways are important for modulation of some of these forces. Many muscles are involved in maintaining upper airway patency by opposing the collapsing forces and are termed upper airway dilator muscles. At least 20 dilator muscles surround the upper airway and are grouped into four as shown in table 1. The first group control tongue protrusion, retraction, elevation, and depression; second group are muscles that retract, stiffen, elevate, and depress the soft palate; third group are muscles that connect to the 
hyoid bone to alter the position of both the tongue and the anterior pharyngeal wall; and fourth group close and stiffen the pharynx. Minor intrinsic muscles within the tongue that alter its shape could also be important. ${ }^{4}$ Increased tongue volume and fat deposition at the base of tongue has also been observed in patients with OSA syndrome. ${ }^{5}$ In OSA, the pharyngeal collapse could be complete (causing apnea) or partial (causing hypopnea).

Table 1: Upper airway dilator muscles

\begin{tabular}{ll}
\hline Muscle action & Muscles involved \\
\hline Tongue movements & Genioglossus \\
& Geniohyoid \\
& Styloglossus \\
& Hyoglossus \\
Soft palate & Levator veli palatini \\
& Palatoglossus \\
& Palatopharyngeus \\
& Tensorveli palatini \\
& Musculus uvulae \\
& Mylohyoid \\
Hyoid bone & Geniohyoid \\
attached muscles & Digastric \\
& Stylohyoid \\
& Omohyoid \\
& Sternohyoid \\
& Thyrohyoid \\
Stiffening of & Superior pharyngeal \\
pharynx & constrictor \\
& Middle pharyngeal \\
& constrictor \\
Tongue retraction & Inferior pharyngeal \\
& constrictor \\
& Intrinsic muscles of tongue \\
& \\
&
\end{tabular}

Treatment: Continuous positive airway pressure (CPAP) therapy is the gold standard and therapy of choice for OSA. Multiple prospective studies and randomized controlled trials have reported its benefit- especially in severe OSA. ${ }^{1}$ This treatment reduces the risk of cardiovascular morbidity and mortality but has adherence rate of $60-70 \%$. Thus, in many patients with severe and moderate OSA this therapy may not be suitable and alternatives are needed. Bi-level positive airway pressure or adaptive servo-ventilation can be used for patients who are intolerant to CPAP but have shown no more benefit than this therapy. Expiratory pressure relief strategies may be useful in some patients. ${ }^{1}$ Other treatments include orodental devices, upper airway surgery, positional therapies and some conservative measures (Table 2).

Table 2: Treatment modalities for OSA

\begin{tabular}{|c|c|}
\hline Groups & Therapeutic modality \\
\hline First line therapy & $\begin{array}{l}\text { Continuous positive airway } \\
\text { pressure (CPAP) therapy } \\
\text { Needs patient motivation, } \\
\text { education, intensive support } \\
\text { and encouragement } \\
\text { Assess for mask leak or } \\
\text { discomfort }\end{array}$ \\
\hline Nasal pathology & $\begin{array}{l}\text { Nasal decongestants, steroids } \\
\text { Septoplasty, polypectomy }\end{array}$ \\
\hline $\begin{array}{l}\text { Insomnia or highly } \\
\text { variable pressure } \\
\text { requirement }\end{array}$ & $\begin{array}{l}\text { Address sleep hygiene } \\
\text { problem, tranquillizers, } \\
\text { Auto-titration positive } \\
\text { airway pressure (Auto CPAP) } \\
\text { Expiratory pressure relief } \\
\text { Bi-level positive airway } \\
\text { pressure (BiPAP) }\end{array}$ \\
\hline $\begin{array}{l}\text { Failed positive } \\
\text { airway pressure } \\
\text { treatment }\end{array}$ & $\begin{array}{l}\text { Oral appliances } \\
\text { Upper airway surgery } \\
\text { Experimental treatment }\end{array}$ \\
\hline $\begin{array}{l}\text { Myofunctional } \\
\text { therapy }\end{array}$ & $\begin{array}{l}\text { Exercises and airways } \\
\text { training (singing, wind } \\
\text { instruments) }\end{array}$ \\
\hline Weight loss & $\begin{array}{l}\text { Diet, exercise, bariatric } \\
\text { surgery }\end{array}$ \\
\hline
\end{tabular}

Myofunctional exercise therapies and Conch blowing: Dilator muscles of the upper airway (Table-1) play a major role in maintaining an open airway during sleep and multiple studies have been performed to assess benefits of exercises and airways training that target oral cavity and oropharyngeal structures. ${ }^{6}$ These exercises involve the soft palate, tongue, and facial muscles and address stomatognathic functions. ${ }^{7}$ The exercises are very complex cascade of isotonic and isometric maneuvers involving soft palate, tongue, facial muscles, breathing, and specific swallowing and chewing actions. Conch (shankha in hindi) blowing has been used for a variety of health ailments. It supposedly provides exercise for urinary tract, bladder, lower abdomen, diaphragm, chest, and neck muscles. ${ }^{8}$ Given the importance of oropharyngeal muscles in pathogenesis of OSA and with previous experience of wind instruments in ameliorating it, ${ }^{6,9,10}$ we 
hypothesized that conch blowing could be useful for improving the severity of OSA.

\section{CASE REPORT}

GR, a 50 year old gentleman presented to us with dullness, weakness, daytime sleepiness and on questioning agreed to excessive snoring. There was a history of recurrent episodes of vertigo (benign positional paroxysmal vertigo) and no history of traffic accidents. He was nondiabetic with stage I hypertension. He is a non-smoker and teetotaler. The pulse was 84 , and regular, average blood pressure of 142/90 $\mathrm{mm}$ of $\mathrm{Hg}$, and normal examination of respiratory, cardiovascular, and neurological systems. The body mass index was $32.0 \mathrm{~kg} / \mathrm{m}^{2}$ and resting $\mathrm{SpO}_{2}$ was 98-99\%. Resting electrocardiogram, treadmill stress test, and pulmonary radiograph was normal. He was advised polysomnographic study and results at baseline are shown in table 3 . He was recommended CPAP therapy. However, despite warnings, he did not agree to the CPAP. He was suggested conch blowing, 5-6 times, twice daily (morning and evening) after proper training from a regular practitioner of this technique.

He was followed up for next 12 months with periodic advice for CPAP and reinforcement of the conch blowing measures. He diligently followed a healthy lifestyle (walking, low fat diet). He was symptomatically better with no dullness, had less snoring (as reported by wife) and daytime sleepiness declined. The body mass index decreased to $30.8 \mathrm{~kg} / \mathrm{m}^{2}$ and blood pressure was $128 / 84$ $\mathrm{mm}$ of $\mathrm{Hg}$ without medication. A polysomnographic study was repeated at 12 months and results are reported in table
3. Significant decline in various OSA indices was observed. The steepest decline was observed in apnea-hypopnea index and respiratory distress index.

\section{DISCUSSION}

Conch is a common name that is applied to medium to large sized shells. The term applies to large snails whose shell has a high spire and a noticeable siphon canal with noticeable point at both ends. ${ }^{11}$ In India, the species commonly referred as conch (shankh) is Turbinella pyrum and other Turbinella species in the family Turbinellidae. In Hindu mythology this is a sacred emblem and is still used as a trumpet. It is one of the eight auspicious symbols in Buddhism and represents the pervasive sound in this religion. Conch shell and its powder has been used for a number of disease conditions without much evidence. ${ }^{11}$ Conch blowing has been reported to be useful for improving general physical well being. ${ }^{8}$ We herein report its use for amelioration of OSA. Our patient had severe OSA as demonstrated by apnea-hypopnea index of $>75 / \mathrm{hr}$. He declined CPAP therapy and with our previous experience in use of this device for OSA we advised him conch-blowing therapy. After 12 months of regular use of this device a significant decline in apnea-hypopnea index and respiratory distress index was observed.OSA is due to weakness of oropharyngeal muscles responsible for airways patency while asleep (Table 1). Myofunctional therapy which involves improvement in tone of various muscles has been reported to be useful. Camacho et al performed a meta-analysis of studies of various oropharyngeal exercise-based interventions to decrease

Table 3: Polysomnography studies at baseline and at 12 months follow-up

\begin{tabular}{lccc}
\hline Variable & Baseline & 12 months & \% change \\
\hline Apnea-hypopnea index & 78.0 & 50.6 & -35.1 \\
Respiratory distress index & 80.2 & 50.6 & -36.9 \\
Apnea index & 67.3 & 30.5 & -54.7 \\
Hypopnea index & 10.8 & 20.1 & +86.1 \\
Oxygen desaturation index & 74.8 & 43.7 & -41.6 \\
Average saturation & 93 & 92 & -1.1 \\
Lowest saturation & 81 & 79 & -2.5 \\
Baseline saturation & 96 & 94 & +2.1 \\
Heart rate average & 68 & 64 & -5.9 \\
Minimum & 51 & 55 & +7.8 \\
Maximum & 116 & 88 & -24.1 \\
Obstructive apneas & $100 \%$ & $90 \%$ & $-10 \%$ \\
Central apneas & -- & $3 \%$ & -- \\
Mixed apneas & -- & $7 \%$ & -- \\
\hline
\end{tabular}


the physiological abnormalities of OSA. ${ }^{6}$ Nine adult studies with 120 patients were reviewed. It was reported that as compared to baseline, myofunctional therapy reduced apnea-hypopnea index from $24.5 \pm 14.3 / \mathrm{hr}$ to 12.3 $\pm 11.8 / \mathrm{hr}(\mathrm{p}<0.0001)$. There was improvement in mean oxygen saturation and snoring as well as Epworth sleepiness scale decreased. Our patient also showed similar benefit.

We can only speculate regarding mechanism of benefit of conch blowing in OSA as no direct studies exist. Mechanistic studies have reported that improvement of genioglossus function using its direct electric stimulation or transcutaneous stimulation, hypoglossal nerve stimulation, non-myorelaxant sedative drugs, and muscle training can improve physiological abnormalities in OSA. ${ }^{4}$ Studies among wind musicians have reported that seven muscles of soft palate: tensor veli palatini, levator veli palatini, palatopharyngeus, palatoglossus, musculus uvulae, superior pharyngeal constrictor and salpingopharyngeus contribute to palatal or pharyngeal closure. ${ }^{12}$ This mechanism may be important in prevention of OSA in double reed musicians. ${ }^{10}$ Regular conch blowing may also reduce tongue fat ${ }^{5}$, and prevent multiple orofacial problems encountered by wind musicians. ${ }^{13}$ Mechanistic studies are required to exactly elicit the physiology of motor response in conch-blowing. Also required are randomized controlled trials with focus on intermediate benefits on physiology of OSA and hard outcomes of cardiovascular and other benefits.

\section{REFERENCES}

1. Jordan AS, McSharry G, Malhotra A. Adult obstructive sleep apnea. Lancet 2014; 383:736-47.

2. Sharma SK, Ahluwalia G. Epidemiology of adult obstructive sleep apnea syndrome in India. Ind J Med Res 2010; 131:171-5.

3. NCD Risk Factor Collaboration (NCD-RiSC). Worldwide trends in children's and adolescents' body mass index, underweight, overweight and obesity, in comparison with adults, from 1975 to 2016: a pooled analysis of 2,416 population-based measurement studies with 128.9 million participants. Lancet 2017; 390:262742 .
4. Cori JM, O'Donoghue F, Jordan AS. Sleeping tongue: current perspectives of genioglossus control in healthy individuals and patients with obstructive sleep apnea. Nat Sci Sleep 2018;10:169-79.

5. Kim AM, Keenan BT, Jackson N, Chan EL, Staley B, Poplani H, et al. Tongue fat and its relationship to obstructive sleep apnea. Sleep 2014;37:1639-48.

6. Camacho M, Certal V, Abdullatif J, Zaghi S, Ruoff CM, Capasso R, et al. Myofunctional therapy to treat obstructive sleep apnea: a systematic review and metaanalysis. Sleep 2015;38:669-75.

7. Guimaraes KC, Drager LF, Genta PR, Marcondes BF, Lorenzi-Filho G. Effects of oropharyngeal exercises on patients with moderate obstructive sleep apnea syndrome. Am J Resp Crit Care Med 2009; 179:962-66.

8. Tarafdar T. Health benefits of blowing a shankh or a conch shell. Available at: http://www.thehealthsite.com/ diseases-conditions/health-benefits-of-blowing-ashankh-or-a-conch-shell-t0817/. Accessed 15 July 2018.

9. Puhan MA, Suarez A, CAscio CL, Zahn A, Heitz M, Braendi O. Didgeridoo playing as alternative treatment for obstructive sleep apnea syndrome: randomized controlled trial. BMJ 2006; 332:266-70.

10. Ward CP, York KM, McCoy JG. Risk of obstructive sleep apnea lower in double-reed wind musicians. J Clin Sleep Med 2012; 8:251-55.

11. Anonymous. Conch. Available at: https://en.wikipedia. org/wiki/Conch. Accessed 15 July 2018.

12. Evans A, Ackerman B, Driscoll. Functional anatomy of the soft palate applied to wind playing. Med Probl Perform Art 2010; 25:183-89.

13. Yeo DKL, Pham TP, Baker J, Porter SAT. Specific orofacial problems experienced by musicians. Austr Dental J 2002; 47:2-11.

\section{Corresponding Author}

Dr Rajeev Gupta, Department of Preventive Cardiology and Internal Medicine, Eternal Heart Care Centre and Research Institute, Jaipur; Academic Research Development Unit, Rajasthan University of Health Sciences, Jaipur, Rajasthan, India.

email:rajeevgg@gmail.com 